\title{
Compulsive exercise: links, risks and challenges faced
}

This article was published in the following Dove Press journal:

Psychology Research and Behavior Management

30 March 2017

Number of times this article has been viewed

\section{Mia Beck Lichtenstein' \\ Cecilie Juul Hinze ${ }^{2}$ \\ Bolette Emborg ${ }^{3}$ \\ Freja Thomsen ${ }^{2}$ \\ Simone Daugaard \\ Hemmingsen ${ }^{4}$}

'Department of Psychology, Faculty of Health Sciences, University of Southern Denmark, ${ }^{2}$ Research Unit for Telepsychiatry and E-mental Health, Mental Health Services in the Region of Southern Denmark, Odense, ${ }^{3}$ Department of Public Health, Aarhus University, Aarhus, ${ }^{4}$ Research Unit, Child and Adolescent Psychiatry, Mental Health Services in the Region of Southern Denmark, Odense, Denmark
Correspondence: Mia Beck Lichtenstein Lichtenstein, J. B. Winsløws Vej 20, 220B, DK-5000 Odense C, Denmark

Tel +45 2 62I 8846

Email mia@mialic.dk
Abstract: Compulsive exercise is a condition described since 1970s. It is characterized by a craving for physical training, resulting in uncontrollable excessive exercise behavior with harmful consequences, such as injuries and impaired social relations. It has not been accepted as a mental disorder in either International Classification of Diseases or Diagnostic and Statistical Manual of Mental Disorders. The aim of this literature review was to critically examine the research on links (comorbidity), risks (negative consequences), and challenges faced (problems in a treatment context). This review found that compulsive exercise is associated with eating disorder pathology, perfectionism, neuroticism, narcissism, and obsessive compulsive traits. The most prominent negative consequences were injuries, social impairment, and depression, but more research is needed to uncover the potential dysfunction resulting from compulsive exercise. As the condition is not recognized as a psychiatric disorder, studies on treatment interventions are sparse. Problems with compliance have been reported; therefore, motivational interviewing has been proposed as a treatment approach, in combination with cognitive behavioral therapy. This review summarizes and discusses findings on links/comorbidity, risks/negative consequences, and treatment challenges. We suggest that future studies should pay attention to both prevention and counseling in sports settings, where compulsive exercise appears, as the condition may be associated with harmful consequences.

Keywords: exercise addiction, measurement, comorbidity, negative consequences, treatment

\section{Introduction}

I got an addict's brain, and when it came to running, I think I got a little carried away. I became a [.... hamster. Seventeen miles a day on a treadmill... I started getting OCD (Obsessive Compulsive Disorder) about the calories, making sure I burned 2,000 every day. Eminem, Men's Health. ${ }^{1}$

In the end I got down to about 149 pounds. I ran to the point where I started to get injured. All the constant pounding from the running began to tear up my hip flexors... I guess I'm pretty compulsive working out. Eminem, Men's Health. ${ }^{1}$

"Compulsive exercise" or "exercise addiction" has been described since 1970s, with William Glasser being the first to report addiction to running. ${ }^{2}$ He suggested that runners develop a positive addiction because of positive psychological effects (eg, joy and pleasure). On the basis of Glasser's report, Carmack and Martens developed a scale to measure commitment to running, and they concluded that running can result in beneficial psychological states. ${ }^{3}$ 
The same year, Morgan questioned whether addiction to running was always positive. ${ }^{4}$ In 1982, Hailey and Bailey were the first to quantify negative addiction in runners. ${ }^{5}$ Since then, growing research has supported that exercise and sport can be taken to extremes, with harmful consequences synthesized in terms of injuries, impairment to health, and affected interpersonal relationships. ${ }^{6}$ It has subsequently been described as a compulsive or addictive behavior, with "links" to eating and affective disorders, with "risks" in terms of continuance in spite of negative consequences (eg, injuries), and "challenges" associated with somatic and psychological treatment.

It has been discussed whether compulsive exercise only appears as a secondary condition to eating disorders, but evidence for the syndrome as a primary condition has been demonstrated and should be understood as a serious psychological morbidity, because psychosocial functioning is impaired. ${ }^{7}$ This discussion will be addressed in the current review.

\section{Definition and theoretic background}

The terminology of the phenomenon has varied with the use of "compulsive exercise", "exercise dependence", "exercise addiction", and "running addiction". ${ }^{8-13}$ It has been suggested that the term "exercise addiction" is the best to describe the condition because it contains both the elements of compulsion and also dependence. ${ }^{14}$ In this review, the terms "compulsive exercise" and "exercise addiction" are used interchangeably, because we address both the compulsive and the addictive nature of the syndrome.

Compulsive exercise is positioned as a mental disorder in the diagnostic manuals neither in Europe, International Classification of Diseases (ICD-10) nor in the USA, Diagnostic and Statistical Manual of Mental Disorders (DSM-5). ${ }^{15,16}$ However, diagnostic criteria were proposed in 1987 by Veale, based on the symptoms of alcohol addiction. ${ }^{17}$ Hausenblas and Downs have also built their research on the Diagnostic and Statistical Manual of Mental Disorders IV (DSM-IV) diagnosis of substance dependence, and defined exercise dependence as a: "multidimensional, maladaptive pattern of exercise, leading to clinically significant impairment, or distress". ${ }^{11}$

This diagnostically based understanding was later replaced by theories of behavioral addictions. Brown raised a model that contained six general characteristics equivalent to all kinds of addictive behaviors. ${ }^{18,19}$ Applied on compulsive exercise patterns, the six criteria are as follows: salience - the exercise becomes the most important thing in life. Conflictrefers to conflicts between the addicted person and those around him/her. Euphoria - the subjective experience of a "buzz" or a "high". Tolerance - increasing amounts of the exercise are needed to achieve the psychological effects. Withdrawal symptoms - unpleasant feelings, such as irritability when the exercise is reduced. Relapse - reversion to earlier, extreme patterns of exercise when trying to cut down on exercise.

\section{Measuring compulsive exercise}

There is still no consensus about the way to identify and categorize the phenomenon. The amount of weekly exercise is not an indicator of compulsive patterns, as the definition states that it is the physical, psychological, and social harm resulting from the exercise that is important. Different questionnaires have been developed to measure negative exercise attitudes and beliefs.

The Negative Addiction Scale (NAS) was the first to measure negative running behavior. ${ }^{5}$ The questionnaire focuses on the "negative" psychological aspects of dependence using a scale of 14 items. High values are associated with higher levels of negative addiction symptoms.

The Obligatory Exercise Questionnaire (OEQ) was developed by Thompson and Pasman to cover a range of exercise behavior and consist of 21 items. $^{20}$ The OEQ was modified from the Obligatory Running Questionnaire by Blumenthal et al and aimed at looking into secondary dependence to portray the main relationship between exercise behaviors and addiction, as well as determining the consequences of exercise addiction. ${ }^{21}$

The Running Addiction Scale (RAS) was designed to measure negative addiction to running. ${ }^{22}$ It consists of 11 items which are responded using a 5-point Likert scale ranging from strongly agree to strongly disagree. Studies validating the RAS have found good psychometric properties. ${ }^{22,23}$

Ogden et al developed The Exercise Dependence Questionnaire (EDQ). ${ }^{24}$ It has 29 items that are rated on a 7-point Likert scale ranging from 1 (strongly disagree) to 7 (strongly agree) with a cut-off point at $\geq 116$. It was developed to measure exercise dependence relevant to all forms of exercise by assessing the motivation to work out, aspiration for good health, the need to control, and problematic exercise behavior. The questionnaire has been used in several studies, for example, the study by Bamber et al. ${ }^{25}$

The Exercise Beliefs Questionnaire (EBQ) is a 21-item scale by Loumidis and Wells that was designed to measure maladaptive beliefs about the consequences of not exercising. ${ }^{26}$ It was developed with exercisers engaging in a wide range of activities. Hausenblas and Downs developed the 
21-item Exercise Dependence Scale (EDS) based on the seven diagnostic criteria for alcohol dependence (eg, tolerance and continuance). ${ }^{11}$ The EDS has been widely used in different exercise settings: Spanish sports centers with people aged 16-60 years, Swedish college students, Portuguese local gyms, and Greek private fitness centers. ${ }^{27-29}$

The Exercise Addiction Inventory (EAI) was developed by Terry et al and consists of six items related to Brown's theoretical concepts of behavioral addiction. ${ }^{13,19}$ The items are rated on a 5-point Likert scale and has a cut-off point $\leq 24$ for the "risk of addiction". It has shown good psychometric properties cross-culturally. ${ }^{30}$

The abovementioned assessment tools have different advantages and limitations. Some only measure one type of sport, for example, running (NAS and RAS), whereas others measure "physical exercise broadly" (EDS and EAI). One is based on diagnostic manuals (EDS) and the other is based on addiction theory (EAI). Some have cut-off points for the "risk of addiction" (EAI and EDQ) while others do not (EDS and EBQ).

Clinical interviewing is suggested as a supplement to examine the false positives (athletes scoring above cut-off on questionnaires, but without any problems), true positives (athletes scoring above cut-off and also reporting impairment), as well as false negatives (athletes scoring below cut-off, but experiencing impairment as a consequence of compulsive exercise) and true negatives (athletes scoring below cut-off and neither reporting compulsive exercise nor any problems related to exercise patterns).

\section{Prevalence of primary compulsive exercise}

Prevalence rates of compulsive/addictive exercise differ according to screening tools and sports samples. Studies have found prevalence proportions of exercise addiction ranging from $3 \%$, through $5-7 \%, 9 \%, 17 \%, 20 \%, 30 \%, 34 \%$, and up to $42 \% .{ }^{13,19,28,29,31-38}$ Mónok et al estimated prevalence proportions in the general adult population to be $0.5 \%{ }^{39}$

The inconsistency in measurement, definition, and sports samples (eg, from runners, students, fitness gym users) makes it difficult to uncover the extent and severity of the syndrome. Also, gender and cultural differences may affect the estimates of prevalence proportions worldwide..$^{30}$

\section{Contextualizing compulsive exercise}

Society influences what we do as individuals. This is also the case when people exercise and when they exercise too much. ${ }^{40}$ According to a study in Great Britain, $14 \%$ of the population attends a gym. ${ }^{41}$ The fitness culture all started with men's bodybuilding. Fitness and bodybuilding were not for everybody. Gradually increasing from the 1980s, this culture commercialized so it became normal to be a fitness member. The commercialization makes people used to the fact that their friends or neighbors exercise. Exercise is now both a personal and social matter, as the individual can be a part of the fitness society by attending to the gym, but has the liberty to exercise as he/she wants. ${ }^{42}$ Global fitness activities such as the ones developed by the fitness organization Les Mills contribute to the feeling of being part of a greater fitness group in the exercising society. Such activities can also contribute to a global body image and body training regime, as they encourage people to exercise in a certain way to achieve a certain (perfect) body shape. ${ }^{43}$

The expanded fitness culture can contextualize the growing interest and emergence of compulsive exercise, and may contribute to the knowledge as to why compulsive exercise exists at all. When we as individuals have an evolutionary drive to belong to a group, and the group is exercising, then the individuals exercise. The exercising society brings body image, body wellness, achievements and competition into the lives of those who engage in exercise. ${ }^{44}$ For some people this may be the way to belong, and the way to show that they matter. The physiognomic assumption of body image is that the way a person looks, mirrors the way a person is. ${ }^{45,46}$ In this context, it becomes an important matter how you look and how you present yourself to others. It can thus be difficult to stop a compulsive exercise pattern, because reducing exercise means cutting down on yourself, your goals for your body, and therefore the impression you leave on others. Featherstone argues that it is an over-simplistic way of understanding body image and argues that affect is a large part of body image and appearance. The affect body image is the small subtle signals we perceive from others: the way they stand, the way they smile, and the way they talk. So even if we have the "perfect body" it is not enough, because there is more to appearance than looks. This adds another dimension to the understanding of compulsive exercise, because it is not just a matter of having the perfect body; it is a matter of doing the right things in addition to the perfect body. If an individual has a perfect body but that this perfection is not congruent with the way the individual feels, it may explain why compulsive exercisers try to exercise to escape from negative emotions - the experience of "a high", mentioned earlier.

In summary, society seems to play an important role in the understanding of the emergence and persistence of 
compulsive exercise, as society may force the individual to strive for the perfect body or the perfect self. Cutting down on exercise may result in exclusion from society, less perfection in looks, and therefore less positive emotions and self-esteem.

\section{Aims of the study}

The purpose of this article was to critically review the literature of primary exercise compulsion/addiction. The aim of this literature review was to interpret and synthesize the published work in the field of compulsive and excessive exercise according to links (comorbid disorders), risks (negative consequences), and challenges faced (in the context of treatment). The aim was to establish an overview of existing knowledge - as well as lack of knowledge - that could be used in future research and clinical interventions.

Previous reviews of the topic are almost 20 years old, and address other important aspects of exercise addiction: definitions and measures, etiological aspects, biological reasons and/or triggers, and methodological limitations. ${ }^{7,10,12,14,47-53}$ One review was made in Spanish and was not translated into English. ${ }^{54}$ The reviews that also contained information on the current aims were included in this literature review.

\section{Methods}

Our literature search was done in the databases PubMed, PsycINFO, and Scopus from August to October 2016. We used the following terms in the search for the condition: "compulsive exercise, exercise addiction, exercise dependence, excessive exercise" in combination with using AND/ OR “definition, measures, prevalence, comorbidity, eating disorder, depression, anxiety, personality, muscle dysmorphia, orthorexia nervosa, pain, injury, illness, social isolation, stress, anxiety, intervention, treatment."

In addition, a manual search of the references cited in selected articles was executed. We aimed to include academic peer-review articles from indexed journals, addressing both quantitative and qualitative exercise research. The data search was not time-restricted, since the oldest papers of this topic are from 1970s.

\section{Links: comorbidity and personality traits}

This section discusses the most well-known and researched comorbidities/syndromes in relation to compulsive exercise: eating disorders, muscle dysmorphia, obsessivecompulsive disorder, specific personality traits, and other addictions.

\section{Eating disorders}

A great deal of the literature on excessive exercise has focused on the links between eating disorders and exercise addiction. For example, the literature review by Demetrovics and Kurimay concluded that exercise addiction and eating disorders have many symptoms in common, and that exercise addiction shows high comorbidity with eating disorders. ${ }^{55}$ The link seems to be the most thoroughly described link in the literature on exercise addiction, probably because this link occurs most often. Actually, compulsive exercise exists so often alongside eating disorders that researchers have speculated that they cannot exist independently from one another at all. Some have argued that exercise addiction is always secondary to an eating disorder and that primary exercise addiction does not exist. ${ }^{56}$ It also seems that $-39 \%-48 \%$ of people with eating disorders engage in compulsive exercise, indicating a common overlap between the two. ${ }^{57}$ Grandi et al concluded that primary compulsive exercisers, especially females, more often than controls presented with dysfunctional eating patterns measured with the Eating Disorder Inventory II (EDI-II). ${ }^{58}$ Associations between drive for thinness/muscularity, compulsive exercise, and body dissatisfaction have also been found in a study exploring female fitspiration bloggers. ${ }^{59}$ This indicates that eating disorder symptoms and compulsive exercise at least share some characteristics, and may thus be part of the same underlying syndrome. Davis and Claridge also found that patients with eating disorders had high scores on an addiction scale, indicating either that eating disorders could be seen as addictions, such as compulsive exercise, or that addictions have high comorbidity with eating disorders. ${ }^{60}$ Furthermore, they found that addictive and obsessive-compulsive traits were associated with weight-preoccupation and excessive exercise in patients with eating disorders.

We, however, argue that there are also a number of differences between eating disorders and compulsive exercise. Since compulsive exercisers primarily place focus on performance over weight loss, they usually consume a sufficient amount of calories, only undergo weight loss if it will boost performance, and do not mind gaining weight when it is in the form of muscles because this aids performance. ${ }^{57}$ Veale distinguished primary from secondary exercise dependence by the absence of an eating disorder. He described secondary exercise dependence as the excessive exercise a person with anorexia nervosa sometimes uses as a means to lose weight. This excessive exercise could reach a state of dependence and, therefore, become secondary exercise dependence. He distinguished primary exercise dependence from eating 
disorders by describing that the exercise is an end in itself and the dieting and weight loss are used to improve performance. Subsequent literature has used the terms primary and secondary exercise addiction. ${ }^{11,61,62}$

In groups where an eating disorder was present, Bamber et al found worse overall morbidity scores (measured on, eg, general health, depression, anxiety, self-esteem, and social dysfunction), than they did in groups where no eating disorder was present. ${ }^{63}$ The compulsive exercisers without an eating disorder mostly resembled healthy controls, indicating overall heavier morbidity in eating disorders than in compulsive exercise. Although it could mean that exercise addiction cannot exist without an eating disorder, it could also suggest that even if compulsive exercise might not represent heavy enough morbidity to classify as a disorder, it appears to be at least a worrying phenomenon that can occur independently from eating disorders. Compulsive exercise appears to signify an equally disturbing, unhealthy, and unattainable body ideal that should be taken seriously by professionals. ${ }^{64}$

The inconsistency in definition makes it difficult for researchers to study the phenomenon, and therefore, difficult to establish a clear classification of compulsive exercise. It seems that compulsive exercise and eating disorders can exist independently from one another and that compulsive exercise can be both primary and secondary to an eating disorder. ${ }^{17,61,62}$

Orthorexia nervosa is defined as an obsession to eat healthy and can be measured with the ORTO-15 self-report questionnaire. ${ }^{65,66}$ The condition has been identified in former patients with eating disorders. ${ }^{67}$ One study looked at orthorexic symptoms in a group of people who exercised regularly and found increased ORTO-15 scores compared to a group of nonexercisers, indicating an extreme healthfocused type of disordered eating among physically active people. ${ }^{68}$ Segura-García et al tested a group of 577 athletes compared to a group of 217 sedentary controls and found an orthorexic prevalence of $28 \%$ for females and $30 \%$ for males in the athletic group, indicating a higher risk for the condition among physically active people, likely because of the importance of nutrition in physical performance. ${ }^{69}$ No studies have yet assessed the association between orthorexia nervosa and compulsive exercise. Future research should explore the potential relationship between the two conditions that seem to take health behavior to extremes.

\section{Muscle dysmorphia}

Muscle dysmorphia (sometimes referred to as "megarexia") is a variant of body dysmorphic disorder, described in the DSM-5 as part of the obsessive-compulsive spectrum. ${ }^{16}$ The condition is characterized by beliefs of insufficient muscularity, and engagement in excessive muscle-building activities, such as weightlifting and using anabolic steroids. Athletes with muscle dysmorphia often have a low fat but increased body mass index and disordered eating habits. ${ }^{70}$ The literature mostly reports male cases, but since the western female body ideal seems to have changed into what can be conceptualized as "strong is the new skinny", it is likely that more females develop the disorder. Muscle dysmorphia can be thought to have commonalities with compulsive exercise due to the extreme focus on achieving fitness goals, but the relationship has not yet been investigated. Research has concluded that little is known about the condition beyond the symptomatic level, and that the area needs consensual, methodological guidelines to unify the research. ${ }^{70}$

\section{Obsessive-compulsive disorder}

Obsessive-compulsive disorder (OCD) is a mental illness characterized by obsessions/compulsions triggered by certain stimuli and the experience of significant distress if the compulsions cannot be maintained. ${ }^{16}$ Compulsive exercise has commonalities with these obsessions and compulsions in terms of craving exercise and severe distress if deprived from exercise. ${ }^{57}$ Obsessions that accompany compulsive behaviors can be compared with the ruminations of an exerciseaddicted person (eg, "If I don't exercise, I will lose muscle fitness, and then I will lose status, and my friends will reject me"). However, it has been argued that addictions are distinguished from OCD, as addictions have the capacity to reduce negative affective states while creating positive effects. For example, even though an addicted exerciser may feel strong compulsions toward working out, the exercise does produce some positive effects, such as the release of endorphins that increase mood and energy level.

Cunningham et al argue that excessive exercise has both addictive and compulsive features, and can exist in both a primary and secondary form. ${ }^{61}$ Their study showed that in its secondary form it was mostly compulsive, and in its primary form mostly addictive. Furthermore, they found that men and women have the same risk. However, the profile for men was often primary and addictive, whereas secondary and compulsive for women. This is in accordance with the fact that more women than men develop an eating disorder. It also supports the notion that compulsive exercise should in some cases be understood as independent from eating disorders and OCD.

Despite the similarities between obsessive-compulsive symptoms and compulsive exercise, only a few studies have examined the relationship. Yet, no studies have examined the 
relationship between OCD and exercise addiction. However, Spano found that persons who had high scores on a test for excessive exercise also had high scores on an OCD test. ${ }^{71}$ Gulker et al found that excessive exercisers rated higher on obsessive-compulsive symptomatology than nonexercisers did. ${ }^{72}$ Future studies on the subject are needed to investigate whether compulsive exercise in some cases appears as a comorbid condition to OCD.

\section{Personality traits}

Studies have identified some similar personality traits in persons who exercise compulsively or are addicted to exercise. Traits, and combinations of traits, are found across addicted exercisers and are hypothesized to play a role in the development and/or maintenance of the condition. "Perfectionism" reduces tolerance for flaws, which can cause a compulsive exerciser never to be satisfied with the performance. ${ }^{73,74}$ "Obsessive/compulsive traits" result in emotional distress if specific patterns cannot be maintained, and can thus trigger anxiety symptoms if the workout schedule cannot be carried out as planned. " "Neuroticism" increases emotional instability/negative emotions, which could increase a compulsive exerciser's focus on working out as the (only) preferred coping mechanism. ${ }^{75,76}$ "Narcissism" causes a high focus on the person's self, so that the compulsive exerciser might prioritize a personal need for working out, despite other equally important obligations such as family and job. ${ }^{71,73}$ "High extraversion" and "low agreeableness", respectively, describe high energy and unwillingness to cooperate, which could be represented by a need to burn energy and uncomprehensiveness when asked to downgrade the exercise in exchange for other tasks. ${ }^{76,77}$

Studies have found some of the same traits in persons with eating disorders, eg, perfectionism and obsessive-compulsive traits. ${ }^{78,79}$ It is not surprising, given the aforementioned commonalities of the two conditions. In a study by Samuels et al, participants with OCD scored higher on neuroticism and lower on agreeableness than healthy controls. ${ }^{80}$ Lichtenstein et al and Hausenblas and Giacobbi also found that low agreeableness and high neuroticism were characteristic for persons with exercise addiction. ${ }^{76,77}$

The shared features of compulsive exercise, eating disorders, and OCD may represent a common underlying risk profile that might manifest as either condition, depending on internal and external stimuli. Knowledge about eating disorders and OCD may guide researchers and therapists in understanding compulsive exercise. It also adds to the important discussion of the possible future placement of compulsive exercise in the diagnostic manuals as either a primary morbid syndrome, or a secondary symptom to other disorders (or maybe only eating disorders, as argued by Bamber et al). ${ }^{25}$

\section{Co-occurring addictions}

Freimuth et al have summed up some of the addictions that can co-occur with exercise addiction, among these are nicotine, alcohol, illicit drugs, buying, sex, and work addictions. ${ }^{57}$ Villella et al assessed behavioral addictions in adolescents. ${ }^{33}$ They found that scores on scales measuring pathological gambling, compulsive buying, internet addiction, work addiction, and exercise addiction were all correlated significantly. In a review from 2011, Sussman et al speculated that $15 \%$ of exercise addicts are also addicted to nicotine, alcohol, and illicit drugs. ${ }^{81}$ Furthermore, they estimated a coexistence of $25 \%$ for exercise addiction and the remaining addictions. They concluded that much more research is needed on the subject. However, it seems that approximately a third of individuals with exercise addiction also exhibit another addiction. ${ }^{81}$

\section{Risks: negative consequences}

This section addresses risks related to compulsive exercise. Risks are defined as potential negative consequences in terms of injury, pain, anxiety, depression, and impairment in social life.

A review by Landolfi highlights some distinctions between healthy levels of exercise and exercise addiction. ${ }^{51}$ The findings suggest that addicted exercisers will continue exercising despite physical injury, marital strain, interference with work, or lack of time for other activities. According to Sachs, individuals who are addicted to exercise are more likely to exercise for intrinsic rewards (they view exercise as a central part of their life and experience withdrawal symptoms when they cannot exercise). ${ }^{82}$ In contrast, committed exercisers perform healthy levels of exercise for extrinsic rewards (they view their exercise as important, but not central to their lives, and they do not suffer from withdrawal symptoms when unable to exercise).

Weinstein and Weinstein address health issues and hazards associated with exercise. ${ }^{52}$ They point out one problem regarding excessive exercise: overuse injuries. Furthermore, they state that people between the ages of 45 and 55 years, who exercise by walking and running several hours a week have a higher risk of developing osteoarthritis than people who are less physically active. They summarize that there are positive effects from regular exercise, but that excessive exercise may have severe physiological and psychological 
consequences, such as overuse injuries, stress, and negative emotions.

\section{Pain and injury}

Veale argued that exercise addiction is most likely found in athletes with persistent physiological injuries. ${ }^{17}$ Veale referred to several studies documenting the physical complications of exercise addiction in long-distance runners. ${ }^{83-85}$ These studies examine physical injuries, such as pressure sores and stress fractures. It can be hypothesized that an addicted athlete, who is prevented from training due to injury, would experience withdrawal symptoms in terms of restlessness and irritability. It seems likely that the addicted athlete would keep exercising in spite of injury, in order to avoid withdrawal symptoms.

In five studies, Hausenblas and Downs validated the EDS $(n=2420) .{ }^{11}$ They found that persons at risk of exercise addiction were more likely to report that they would exercise in spite of bad weather, pain, or discomfort, than nonaddicted responders. This shows that exercising in spite of injuries and pain seems characteristic for people suffering from exercise addiction. Other studies have investigated the psychological risk factors associated with ignoring physical pain and injury. ${ }^{86-88}$ These studies illustrate that "type A behavior" impacts on the risk of suffering from stress fractures and repeated injuries due to running, because pain and injuries are ignored. Type A behavior is characterized by over-theaverage energy, aggressiveness, impatience, competitiveness, and hostility. ${ }^{86,88,89}$ Based on these findings, it is suggested that runners with type A behavior suffer from more injuries and are more likely to get stress fractures related to running than others are..$^{90}$

Exercising despite injury and the pain symptomatology of compulsive exercise is also illustrated in a case study of a 25 -year-old woman. ${ }^{91}$ It is described how in the past 5 years she has exercised increasingly and that pain in her arm worries her, because it does not get enough time to heal between competitions. She is advised by her doctor to give up sports, due to the risk of permanently damaging her arm. She feels it is impossible to reduce her exercise.

Given these findings, it seems likely that compulsive exercisers can be characterized as persons with a competitive personality who are prone to exercise in spite of pain and injury, even if it threatens their physical well-being permanently.

\section{Social impairment}

When exercise is first priority, interpersonal relations can be negatively influenced and lead to social isolation as friends and family are deselected. Literature regarding the social consequences of compulsive exercise is sparse. However, there are theories (eg, Brown) and measuring devices for compulsive exercise/exercise addiction/exercise dependence which emphasize social conflicts/social impairment as central issues regarding the phenomenon (EAI, EDS). ${ }^{11,13,18}$ In the aforementioned case study, it is also described how the young woman experiences conflicts in her social life due to her exercise. Her relationship with her partner has broken down, she has lost her friends, and it has become almost impossible for her to continue her education and work.

A study of Chinese college students investigated the influence of compulsive exercise on psychological health in terms of anxiety, depression, and subjective well-being. ${ }^{92}$ Subjective well-being is defined through eight parameters: 1) selfsatisfaction, 2) negative mood, 3) life satisfaction, 4) social behavior, 5) energy, 6) positive mood, 7) interpersonal relationship, and 8) family satisfaction. Li et al found that students with exercise addiction more significantly presented with lower self-satisfaction, negative mood/energy, and social behavior than students without exercise addiction did. These findings suggest that exercise addiction can cause increased negative mood and increased social isolation in college students. However, this cross-sectional study does not measure causality, only associations. Therefore, it is not possible to determine if negative mood led to exercise addiction or was the result of an addiction. Furthermore, it is unclear if social isolation is caused by negative mood, or low self-satisfaction, or any other factor in the students' lives. Additionally, it is not clear how social behavior, life satisfaction, interpersonal relationships, and family satisfaction are operationalized in this particular study. The findings are nevertheless important because they enlighten some of the psychological factors involved in compulsive and addictive exercise.

\section{Anxiety and depression}

In the study from China, the participants with scores equal to or above 24 on EAI scored significantly higher on state anxiety than the non-addicted group. The exercise-addicted group also had significantly higher depression scores than the nonaddicted group. Weinstein et al explored the relationship between compulsive exercise, anxiety, and depression in physically active individuals, both professionals and amateurs. ${ }^{9}$ The purpose of the study was also to investigate if there was a difference between professionals and amateurs in ratings of compulsive exercise, anxiety, and depression. They found that levels of compulsive exercise and levels of depression were positively correlated in both professionals 
and amateurs, and that professional athletes showed higher depression scores than amateurs. Weinstein et al highlight that there are no baseline measures from before the individuals became compulsive exercisers, therefore causal association still remain to be investigated..$^{9}$ They also suggest that the performance pressure for professionals can lead to feelings of depression and helplessness, and that this could be the reason why professionals experience more depressive symptoms than amateurs.

In summary, when addressing compulsive exercise and exercise addiction, the literature is sparse with respect to potential negative consequences. Findings do pinpoint several negative somatic consequences such as stress fractures, and evidence suggests some psychological symptoms (eg, low self-satisfaction and anxiety) in athletes with exercise addiction. Yet no studies have been developed to test the causal associations between compulsive exercise and somatic or psychosocial impairment. Future longitudinal studies are requested to assess self-satisfaction, depression and anxiety before and after the development of compulsive exercise patterns.

\section{Challenges: treatment}

Our literature search addressing compulsive exercise/exercise addiction and intervention/treatment found no literature hits with this specific focus. However, treatment approaches are demanded by clinicians, sports injury professionals and academic researchers. ${ }^{50}$

In a treatment context, it is a challenge that compliance and motivation for changing exercise patterns are ambivalent. Lichtenstein et al described potential treatment problems, as addicted exercisers are characterized by having low degrees of compliance in their personality profiles.

Compulsive exercise can lead to injuries and physiotherapists might be the first professionals to meet over-trained athletes. Adams and Kirkby interviewed 24 sports physiotherapists about problems and strategies in the treatment of addicted patients. ${ }^{93}$ The majority of the respondents $(71 \%)$ reported compliance problems with respect to reducing exercise as a part of the injury treatment. The strategies used to treat those with a compulsion for exercise were 1) explanation/education, eg, warning about physical consequences if exercise was continued at the same level, 2) prescribing alternative training activities, and/or 3) referral for psychological treatment. The study suggests that psychological approaches are most recommended in the treatment of exercise addiction.

Adams et al suggested that psychotherapeutic interventions should focus on cognitive processing and behavioral management with respect to the intense fear of losing control related to compulsions. ${ }^{50}$ The intervention should consist of identifying the compulsive exercise and the triggers, understanding the health benefits of exercise moderation, empowering the patient to develop a self-management strategy, and rebuilding coping strategies. Studies that test this treatment approach in randomized controlled trials are still needed.

Education in the mechanisms of exercise compulsions and the need for rest to avoid overtraining are recommended by Adams as part of the psychotherapeutic interventions. ${ }^{10}$ This first step is described as being necessary for the acknowledgement of the need to change, and to enhance motivation. Next, motivational interviewing and cognitive behavioral therapy is recommended, as it has received empirical support for the treatment of behavioral addictions. Studies testing these psychotherapeutic interventions are also still needed. Thus, it is concluded that specialists in behavioral addictions and health psychologists are recommended as therapists, because they have expertise in modifying unhealthy behavior.

Weinstein and Weinstein also recommended that motivation is addressed, and that a cognitive behavioral approach is taken. ${ }^{52}$ Behavioral strategies are suggested, eg, rewarding lower levels of exercise. They also point out the importance of assessing comorbid disorders, eg, eating disorders. The aim of the treatment is to return to moderate exercise and/or replace it with new forms of exercise. Neither part of these advices have been evaluated scientifically.

Pharmacological treatment for compulsive exercise has been reported in one case study. ${ }^{94}$ The patient presented was a 47-year-old male, diagnosed with bipolar disorder and compulsive exercise despite injuries, illness, and social isolation. He was treated with up to $600 \mathrm{mg} /$ daily of the antipsychotic quetiapine. After 12 weeks, his symptoms significantly improved and after 24 weeks, they were resolved with a reduction in EAI score from 28 to 12 . The study concluded that quetiapine as an add-on treatment is an option for patients with bipolar disorder and compulsive behavior. However, studies on medication for compulsive exercise need further attention, as this case report is still the only one.

Summarizing the challenges in providing treatment, the main problems are low patient compliance and the lack of empirical tests of therapeutic and medical interventions. The literature hypothesizes that motivation interviewing and cognitive behavioral therapy might be helpful, but before we can recommend treatment we need to understand more about the varying forms of compulsive exercise and the difficulties (such as lowered mood, unsatisfying relationships, and dysfunctional personality traits) that accompany this form of 
behavioral suffering. Other treatment methods should also be evaluated since compulsive exercise is a complex condition with varying etiology and comorbidity. The primary outcome measures must be reduced exercise levels and also healthier coping strategies. Effective and successful treatment interventions are expected to prevent overload injuries, and ensure that job and social relationships are maintained.

\section{Summary and future directions}

We have conducted a literature review on compulsive exercise and exercise addiction with special attention to links, risks, and challenges in providing treatment. We found that the definition and measurement of compulsive exercise and exercise addiction still lack consensus, and so it is difficult to study potential comorbidity and negative consequences, as well as treatment. However, as concluded in previous work, the condition seems to be linked to eating disorder pathology, emotional problems, and certain personality traits, with perfectionism, narcissism, and neuroticism as the most valid findings. This literature review has overlaps with previous work, because the field lacks new research. Especially the link with OCD needs to be explored in future studies. Further research and clinical interviewing is also needed to examine whether compulsive exercise is associated with harmful consequences and impairment in daily functioning. The existing literature is sparse and inconclusive. If severe distress is found to be a result of compulsive exercise and exercise addiction, it could be argued that the condition should be understood as a distinct mental disorder. Treatment options and effect studies do not exist to date, but are requested.

Our results are interpretations and syntheses of the published work within this field. Szabo et al found that there were 40 publications per year on exercise addiction in the period from January 2011 to January 2014, in 89 different journals. We have aimed to demonstrate that we are examining our sources and our own interpretations with a critical approach.

The term "synthesis" refers to bringing together material from different sources and creating an integrated whole..$^{95}$ The synthesis is the interpretation of the interpretations that we have gone through in the literature study. As this review is a literature study, and not a systematic review, we have not conducted a systematic literature search following the PRISMA guidelines. However, we have described the method and our search terms, and so we believe that our results can be directive for future systematic reviews, meta-analyses, or empirical research. It is noteworthy that only one of the existing reviews is a systematic review, and only two specify their search terms and databases used. . $^{12,51}$

\section{Limitations}

The field of compulsive or addictive exercise is restricted, due to a lack of conceptual and methodological consistency. This is an essential limitation for all research about this phenomenon. The findings of this article should therefore be interpreted with these limitations in mind. It is suggested that the main purpose of future research should be to explore if and when compulsive exercise is harmful, and to establish unity in the definition and identification of the primary syndrome. This will create a base for conducting controlled, randomized trials, testing the effect of different treatment approaches. It is important to consider the motivation for treatment and compliance, because compulsive exercise patterns are linked to certain profound personality traits and serve as a way of coping with emotional (or psychiatric) problems.

\section{Disclosure}

The authors report no conflicts of interest in this work.

\section{References}

1. Healy M. How eminem beat addiction with exercise; 2015. Available from: http://www.mensjournal.com/magazine/eminem-the-homebody-20150731. Accessed January 30, 2017.

2. Glasser W. Positive Addiction. New York, NY: Harper and Row; 1976.

3. Carmack MA, Martens R. Measuring commitment to running: a survey of runners' attitudes and mental states. J Sports Psychol. 1979;1(1):25-42.

4. Morgan WP. Negative addiction in runners. Physician Sportsmed. 1979;7(2):57-70.

5. Hailey BJ, Bailey LA. Negative addiction in runners: a quantitative approach. J Sport Behav. 1982;5(3):150-154.

6. Furst DM, Germone K. Negative addiction in male and female runners and exercisers. Percept Mot Skills. 1993;77(1):192-194.

7. Szabo A, Griffiths MD, de La Vega Marcos R, Mervo B, Demetrovics Z. Methodological and conceptual limitations in exercise addiction research. Yale J Biol Med. 2015;88(3):303-308.

8. Murray SB, Maguire S, Russell J, Touyz SW. The emotional regulatory features of bulimic episodes and compulsive exercise in muscle dysmorphia: a case report. Eur Eat Disord Rev. 2012;20(1):68-73.

9. Weinstein A, Maayan G, Weinstein Y. A study on the relationship between compulsive exercise, depression and anxiety. J Behav Addict. 2015; 4(4):315-318.

10. Adams J. Understanding exercise dependence. J Contemp Psychother. 2009;39(4):231-240.

11. Hausenblas HA, Downs DS. How much is too much? the development and validation of the exercise dependence scale. Psychol Health. 2002;17(4):387.

12. Hausenblas HA, Downs DS. Exercise dependence: a systematic review. Psychol Sport Exerc. 2002;3(2):89-123.

13. Terry A, Szabo A, Griffiths M. The exercise addiction inventory: a new brief screening tool. Addict Res Theory. 2004;12(5):489-499.

14. Berczik K, Szabo A, Griffiths M, et al. Exercise addiction: symptoms, diagnosis, epidemiology, and etiology. Substance Use Misuse. 2012;47(4):403-417.

15. WHO. ICD-10 - International Statistical Classification of Diseases and Related Health Problems. Tenth Revision. Geneva: WHO; 2004. Vol 2.

16. American Psychiatric Association. Diagnostic and Statistical Manual of Mental Disorders. 5th ed. Washington, DC: American Psychiatric Association; 2013.

17. Veale DMW. Exercise Dependence. Brit J Addict. 1987;82(7):735-740. 
18. Brown RIF. Some contributions of the study of gambling to the study of other addictions. In: Eadington WR, Cornelius JA, editors. Gambling Behaviour and Problem Gambling. 1st ed. Reno, NV: University of Nevada Press; 1993:241-272.

19. Brown I. A theoretical model of the behavioural addictions - applied to offending. In: Hodge JE, McMurran M, Hollin RC, editors. Addicted to Crime. 1st ed. Chichester, West Sussex, England: Wiley; 1997:13-65.

20. Thompson JK, Pasman L. The Obligatory Exercise Questionnaire. Behav Assess Rev. 1991;14:137.

21. Blumenthal JA, O'Toole LC, Chang JL. Is Running an analogue of anorexia nervosa? an empirical study of obligatory running and anorexia nervosa. Obstet Gynecol Surv. 1985;40(2):94-95.

22. Chapman CL, De Castro JM. Running addiction: measurement and associated psychological characteristics. J Sports Med Phys Fitness. 1990;30(3):283-290.

23. Sancho AZ, Ruiz-Juan F. Psychometric properties of the Spanish version of the Running Addiction Scale (RAS). Span J Psychol. 2011; 14(02):967-976.

24. Ogden J, Veale D, Summers Z. The development and validation of the Exercise Dependence Questionnaire. Addict Res. 1997;5(4):343-355.

25. Bamber DF, Cockerill Im FAU, Carroll D. The pathological status of exercise dependence. Br J Sports Med. 2000;34(2):125-132.

26. Loumidis KS, Wells A. Assessment of beliefs in exercise dependence: the development and preliminary validation of the exercise beliefs questionnaire. Pers Individ Dif. 1998;25(3):553-567.

27. Sicilia A, Gonzalez-Cutre D. Dependence and physical exercise: Spanish validation of the Exercise Dependence Scale-Revised (EDS-R). SpanJPsychol. 2011;14(1):421-431.

28. Lindwall M, Palmeira A. Factorial validity and invariance testing of the exercise dependence scale-revised in Swedish and Portuguese exercisers. Meas Phys Educ Exerc Sci. 2009;13(3):166-179.

29. Parastatidou IS, Georgios D, Theodorakis Y, Vlachopoulos SP. Addicted to exercise: psychometric properties of the exercise dependence scalerevised in a sample of a Greek exercise participants. Eur J Psychol Assess. 2012;28(1):3-10.

30. Griffiths MD, Urbán R, Demetrovics Z, et al. A cross-cultural reevaluation of the exercise addiction inventory (EAI) in five countries. Sports Med Open. 2015;1(1):1-7.

31. Griffiths MD, Szabo A, Terry A. The exercise addiction inventory: a quick and easy screening tool for health practitioners. Br J Sports Med. 2005;39(6):e30.

32. Lichtenstein MB, Jensen TT. Exercise addiction in crossfit: prevalence and psychometric properties of the exercise addiction inventory. Addict Behav Rep. 2016;3:33-37.

33. Villella C, Martinotti G, Di Nicola M, et al. Behavioural addictions in adolescents and young adults: results from a prevalence study. $J \mathrm{Gambl}$ Stud. 2011;27(2):203-214.

34. Szabo A, Vega Rde L, Ruiz-BarquIn R, Rivera O. Exercise addiction in Spanish athletes: investigation of the roles of gender, social context and level of involvement. J Behav Addict. 2013;2(4):249-252.

35. Youngman J. Risk for exercise addiction: a comparison of triathletes training for sprint-, olympic-, half-ironman, and ironman-distance triathlons. Open access diss; 2007-12-20. Available from: http://scholaryrepository.miami.edu/oa_dissertations/12, University of Miami; 2014. Accessed March 1, 2017.

36. Lejoyeux M, Guillot C, Chalvin F, Petit A, Lequen V. Exercise dependence among custumers from a parisian sport shop. J Behav Addict. 2012;1(1):28-34.

37. McNamara J, McCabe MP. Striving for success or addiction? Exercise dependence among elite Australian athletes. J Sports Sci. 2012; 30(8):755-766.

38. Lejoyeux M, Avril M, Richoux C, Embouazza H, Nivoli F. Prevalence of exercise dependence and other behavioral addictions among clients of a Parisian fitness room. Compr Psychiatry. 2008;49(4):353-358.

39. Mónok K, Krisztina B, Róbert U, et al. Psychomoetric properties and concurrent validity of two exercise addiction measures: a population wide study. Psychol Sport Exerc. 2012;13(6):739-746.
40. Booth SL, Sallis JF, Ritenbaugh C, et al. Environmental and societal factors affect food choice and physical activity: rationale, influences, and leverage points. Nutr Rev. 2001;59(3):S21-S36.

41. Crossley N. In the gym: motives, meaning and moral careers. Body Soc. 2006;12(3):23-50.

42. Andreasson J, Johansson T. The fitness revolution. Historical transformations in the global gym and fitness culture. Sport Sci Rev. 2014;23(3-4):91-111.

43. Dworkin S. Body Panic : Gender, Health, and the Selling of Fitness. New York, NY: New York University Press; 2009.

44. Featherstone M. Body, image and affect in consumer culture. Body Soc. 2010;16(1):193-221.

45. Rivers C. Face Value Physiognomical Thought and the Legible Body in Marivaux, Lavater, Balzac, Gautier, and Zola. Madison, WI: Universit of Wisconsin Press; 1994.

46. Twine R. Physiognomy, phrenology and the temporality of the body. Body Soc. 2002;8(1):67-88.

47. Adams J, Kirkby RJ. Exercise dependence: a review of its manifestation, theory and measurement. Sports Med Training Rehab. 1998;8(3):265-276.

48. Allegre B, Souville M, Therme P, Griffiths M. Definitions and measures of exercise dependence. Addict Res Theory. 2006;14(6):631-646.

49. Adams J, Kirkby RJ. Excessive exercise as an addiction: a review. Addict Res Theory. 2002;10(5):415-437.

50. Adams JM, Miller TW, Kraus RF. Exercise dependence: diagnostic and therapeutic isues for patients in psychotherapy. J Contemp Psychother. 2003;33(2):93-107.

51. Landolfi E. Exercise addiction. Sports Med. 2013;43(2):111-119.

52. Weinstein A, Weinstein Y. Exercise addiction- diagnosis, bio-psychological mechanisms and treatment issues. Curr Pharm Des. 2014; 20(25):4062-4069.

53. Egorov AY, Szabo A. The exercise paradox: an interactional model for a clearer conceptualization of exercise addiction. $J$ Behav Addict. 2013;2(4):199-208.

54. Marquez S, de la Vega R. La adicción al ejercicio: un trastorno emergente de la conducta [Exercise addiction: an emergent behavioral disorder]. Nutricion hospitalaria. 2015;31(6):2384-2391. Spanish.

55. Demetrovics Z, Kurimay T. Testedzéfüggöség: a sportolás mint addikció [Exercise addiction: a literature review]. Psychiatr Hung. 2008;23(2):129-141. Hungarian.

56. Bamber D, Cockerill IM, Rodgers S, Carroll D. "It's exercise or nothing": a qualitative analysis of exercise dependence. Br J Sports Med. 2000;34(6):423-430.

57. Freimuth M, Moniz S, Kim SR. Clarifying exercise addiction: differential diagnosis, co-occurring disorders, and phases of addiction. Int J Environ Res Public Health. 2011;8(10):4069-4081.

58. Grandi S, Clementi C, Guidi J, Benassi M, Tossani E. Personality characteristics and psychological distress associated with primary exercise dependence: an exploratory study. Psychiatry Res. 2011;189(2): 270-275.

59. Holland G, Tiggemann M. "Strong beats skinny every time": disordered eating and compulsive exercise in women who post fitspiration on instagram. Int J Eat Disord. 2016;50(1):76-79.

60. Davis $\mathrm{C}$, Claridge $\mathrm{G}$. The eating disorders as addiction: a psychobiological perspective. Addict Behav. 1998;23(4):463-475.

61. Cunningham HE, Pearman S 3rd, Brewerton TD. Conceptualizing primary and secondary pathological exercise using available measures of excessive exercise. Int J Eat Disord. 2016;49(8):778-792.

62. Zmijewski CF, Howard MO. Exercise dependence and attitudes toward eating among young adults. Eat Behav. 2003;4(2):181-195.

63. Bamber D, Cockerill IM, Carroll D. The pathological status of exercise dependence. Br J Sports Med. 2000;34(2):125-132.

64. Bell HS, Donovan CL, Ramme R. Is athletic really ideal? An examination of the mediating role of body dissatisfaction in predicting disordered eating and compulsive exercise. Eat Behav. 2016;21:24-29.

65. Dunn TM, Bratman S. On orthorexia nervosa: a review of the literature and proposed diagnostic criteria. Eat Behav. 2016;21:11-17. 
66. Donini LM, Marsili D, Graziani MP, Imbriale M, Cannella C. Orthorexia nervosa: validation of a diagnosis questionnaire. Eat Weight Disord. 2005;10(2):e28-e32.

67. Segura-Garcia C, Ramacciotti C, Rania M, et al. The prevalence of orthorexia nervosa among eating disorder patients after treatment. Eat Weight Disord. 2015;20(2):161-166.

68. Dalmaz M, Yazar Soyadı YA, YurtdaŞ TG. Prevalence of orthorexia nervosa symptoms among people who exercise in gyms. Int Ref J Ortho Traumatology Sports Med. 2015;4:23-23.

69. Segura-García C, Papaianni MC, Caglioti F, et al. Orthorexia nervosa: a frequent eating disordered behavior in athletes. Eat Weight Disord. 2012;17(4):e226-e233.

70. Tod D, Edwards C, Cranswick I. Muscle dysmorphia: current insights. Psychol Res Behav Manag. 2016;9:179-188.

71. Spano L. The relationship between exercise and anxiety, obsessivecompulsiveness, and narcissism. Pers Individ Dif. 2001;30(1):87-93.

72. Gulker MG, Laskis TA, Kuba SA. Do excessive exercisers have a higher rate of obsessive-compulsive symptomatology? Psychol Health Med. 2001;6(4):387-398.

73. Miller KJ, Mesagno C. Personality traits and exercise dependence: exploring the role of narcissism and perfectionism. Int J Sport Exerc Psychol. 2014;12(4):368-381.

74. Coen SP, Ogles BM. Psychological characteristics of the obligatory runner: a critical examination og the anorexia analogue hypothesis. J Sport Exerc Psychol. 1993;15(3):338-354.

75. Andreassen CS, Griffiths MD, Gjertsen SR, Krossbakken E, Kvam S, Pallesen $\mathrm{S}$. The relationships between behavioral addictions and the five-factor model of personality. J Behav Addict. 2013;2(2):90-99.

76. Hausenblas H, Giacobbi PR Jr. Relationship between exercise dependence symptoms and personality. Pers Individ Dif. 2004;36(6): 1265-1273.

77. Lichtenstein MB, Christiansen E, Elklit A, Bilenberg N, Stoving RK. Exercise addiction: a study of eating disorder symptoms, quality of life, personality traits and attachment styles. Psychiatry Res. 2014;215(2):410-416

78. Ashby JS, Kottman T, Schoen E. Perfectionism and eating disorders reconsidered. J Ment Health Couns. 1998;20(3):261-271.

79. Newton JR, Freeman CP, Munro J. Impulsivity and dyscontrol in bulimia nervosa: is impulsivity an independent phenomenon or a marker of severity? Acta Psychiatr Scand. 1993;87(6):389-394.
80. Samuels J, Nestadt G, Bienvenu OJ, Costa PT, Riddle MA, Liang K. Personality disorders and normal personality dimensions in obsessivecompulsive disorder. Br J Psychiatry. 2000;177:457-462.

81. Sussman S, Lisha N, Griffiths M. Prevalence of the addictions: a problem of the majority or the minority? Eval Health Prof. 2011;34(1):3-56.

82. Sachs ML, Pargman D. Running addiction: a depth interview examination. J Sport Behav. 1979;2:143-155.

83. Colt EW, Spyropoulos E. Running and stress fractures. $\mathrm{Br} \mathrm{Med} J$. 1979;2(6192):706.

84. Stanish WD. Overuse injuries in athletes: a perspective. Med Sci Sport Exerc. 1984;16(1):1-7.

85. Liberman RB, Palek J. Hematologic abnormalities simulating anorexia nervosa in an obligatory athlete. Am J Med. 1984;76(5):950-952.

86. Carver CS, Coleman AE, Glass DC. The coronary-prone behavior pattern and the suppression of fatigue on a treadmill test. J Pers Soc Psychol. 1976;33(4):460-466.

87. Hassmen P, Stahl R, Borg G. Psychophysiological responses to exercise in type A/B men. Psychosom Med. 1993;55(2):178-184.

88. Byrne DG. Type A behaviour, anxiety and neuroticism: reconceptualizing the pathophysiological paths and boundaries of coronary-prone behaviour. Stress Med. 1996;12:227-238.

89. Rosenman RH. Type A behavior pattern: a personal overview. J Soc Behav Pers. 1990;5:1-24.

90. Ekenman I, Hassmen P, Koivula N, Rolf C, Fellander-Tsai L. Stress fractures of the tibia: can personality traits help us detect the injuryprone athlete? Scand J Med Sci Sports. 2001;11(2):87-95.

91. Griffiths M. Exercise addiction: a case study. Addict Res. 1997;5(2): $161-168$.

92. Li M, Nie J, Ren Y. [Effects of exercise dependence on psychological health of Chinese college students]. Psychiatria Danubina. 2015; 27(4):413-419. Polish.

93. Adams J, Kirkby R. Exercise dependence: a problem for sports physiotherapists. Aust J Physiother. 1997;43(1):53-58.

94. Di NM, Martinotti G, Mazza M, Tedeschi D, Pozzi G, Janiri L. Quetiapine as add-on treatment for bipolar I disorder with comorbid compulsive buying and physical exercise addiction. Prog Neuropsychopharmacol Biol Psychiatry. 2010;34(4):713-714.

95. Merriam S. Case Study Research in Education: A Qualitative Approach. San Francisco, CA: Jossey-Bass; 1988.
Psychology Research and Behavior Management

\section{Publish your work in this journal}

Psychology Research and Behavior Management is an international, peerreviewed, open access journal focusing on the science of psychology and its application in behavior management to develop improved outcomes in the clinical, educational, sports and business arenas. Specific topics covered in the journal include: Neuroscience, memory and decision making; Behavior modification and management; Clinical applications; Business and sports performance management; Social and developmental studies; Animal studies. The manuscript management system is completely online and includes a very quick and fair peer-review system, which is all easy to use. Visit http://www. dovepress.com/testimonials.php to read real quotes from published authors. 